\title{
ENFRENTAMIENTO IMAGINOLOGICO DE LAS LESIONES CEREBRALES EN PACIENTES VIH
}

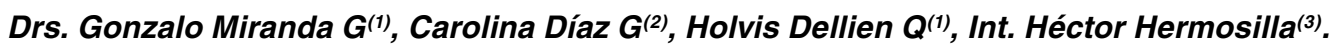

1. Neurorradiólogo, Hospital Clínico Universidad de Chile.

2. Becada Inmunología Clínica, Hospital Clínico Universidad de Chile.

3. Interno de Medicina, Universidad de Chile.

\section{IMAGING APPROACH TO BRAIN LESIONS IN HIV PATIENTS}

\begin{abstract}
Human immunodeficiency virus (HIV) is a neurotropic virus that crosses the blood-brain barrier at early stages of the disease. Thus, the central nervous system (CNS) constitutes the major target of HIV, and according to estimations approximately two-thirds of patients will develop CNS involvement during the course of their disease. CNS diseases spectrum is wide and can be categorized into primary effects of HIV, opportunistic infections, neoplasms and vascular disease. A prompt diagnosis and treatment of such disorders is critical. Imaging studies play a crucial role in the diagnostic process. Therefore, characteristics of neuro-images in patients with HIV and their neurological manifestations have been reviewed.

Keywords: Differential diagnosis, Neuro-images, HIV.
\end{abstract}

Resumen: El virus de inmunodeficiencia humana (VIH) es un virus neurotrópico que cruza la barrera hemato-encefálica en etapas precoces de la enfermedad. Es así como el sistema nervioso central (SNC) es blanco mayor del virus VIH, estimándose que aproximadamente dos tercios de los pacientes desarrollarán compromiso del SNC durante el curso de su enfermedad. El espectro de enfermedades del SNC es amplio y puede ser categorizado en: compromiso directo del virus $\mathrm{VIH}$, infecciones oportunistas, neoplasias y enfermedad vascular. Un pronto diagnóstico y tratamiento de tales desordenes es crítico. Los estudios de imágenes juegan un rol crucial en el diagnóstico. Hemos revisado las características de las neuroimágenes en los pacientes $\mathrm{VIH}$ y sus

Miranda G. Enfrentamiento imaginológico de las lesiones cerebrales en pacientes VIH. Rev Chil Radiol 2008; 14: 200-207.

Correspondencia: Dr. Gonzalo Miranda G.

Santos Dumont 999. Santiago de Chile

gomiranda2000@yahoo.com

Trabajo recibido el 28 de abril de 2008, aceptado para publicación el 11 de noviembre de 2008. manifestaciones neurológicas.

Palabras clave: Diagnóstico diferencial, Neuroimágenes, $\mathrm{VIH}$.

\section{Introducción}

El síndrome de inmunodeficiencia adquirida (SIDA) fue descrito por primera vez en el año 1981 y desde entonces se ha evidenciado un explosivo incremento del número de casos a nivel mundial, superando actualmente los 40 millones de personas infectadas. Se estima que sólo en el año 2007, cinco millones de personas contrajeron el virus ${ }^{(1)}$.

Por su parte, la distribución de los casos de $\mathrm{VIH} / \mathrm{SIDA}$ muestra marcadas diferencias regionales. África subsahariana continúa siendo la región más afectada, con aproximadamente 25,8 millones de personas infectadas; en Europa se considera como una epidemia en rápido crecimiento, al igual que lo que sucede en Asia central y oriental. En América Latina y el Caribe se estima actualmente que más de 2 millones de individuos padecen de esta infección, siendo las relaciones sexuales entre hombres la principal modalidad de transmisión en la región, seguida por la drogadicción endovenosa; sin embargo, desde los años 90 se aprecia un incremento de la transmisión heterosexual(1).

En Chile, el primer caso de SIDA se diagnosticó en el año 1984 y desde entonces la notificación de casos ha ido en constante aumento. Es así como entre 1984 y diciembre del 2004 se registraron 14.611 casos, con una incidencia anual de 103 casos $/ 100.000$ habitantes. La principal vía de transmisión continúa siendo la sexual, estando la conducta homosexual y bisexual presente en el 45 y $14 \%$ respectivamente. El grupo etario más afectado corresponde a individuos entre 20 y 49 años, que concentran el $86 \%$ de los casos. No se observan diferencias significativas entre ambos sexos en relación a la edad al momento del diagnóstico ${ }^{(2)}$. En el año 2007, las defunciones por SIDA en nuestro país correspondieron al $0,46 \%$ del total, proporción levemente inferior al año anterior $(0,51 \%)$. Es esperable que las nuevas políticas nacionales de acceso universal a los tratamientos anti-retrovirales permitan mejorar más estos indicadores ${ }^{(2)}$. 


\section{Características generales del VIH}

EI VIH corresponde a un retrovirus que infecta principalmente a un subgrupo de los linfocitos $T$, los denominados linfocitos T CD4, por el marcador de superficie que presentan a nivel de la membrana plasmática, una molécula expresada en forma constitucional en éstos, que además es utilizada como receptor de agente viral, específicamente de la glicoproteína 120 (GP120) que se ubica en la superficie de este agente viral. Dado que infectan este tipo de células $T$, afectan cuali y cuantitativamente el sistema inmune, desencadenando un severo estado de inmunosupresión con el paso de los años.

Este virus es capaz de infectar a otros tipos celulares, del tipo no linfoide, que también expresan el receptor CD4, como son los macrófagos, las células dendríticas de la piel y la microglia, entre otras.

Como se desprende de lo anterior, el VIH/SIDA corresponde a una enfermedad sistémica, que se caracteriza por tener como mecanismo patogénico tanto la infección celular directa por el virus como la provocación de un severo estado de inmunosupresión, que predispone a numerosas infecciones oportunistas así como también a patología tumoral y autoinmune. Por el primer mecanismo, la afección del sistema nervioso central (SNC) conduce a la encefalopatía $\mathrm{VIH}$, mientras que el segundo se observa en los casos de toxoplasmosis y de linfoma primario.

Según los datos existentes, se estima que entre un $30-40 \%$ de los pacientes VIH sufre o sufrirá de síntomas neurológicos en el curso de su enfermedad y sin embargo, el compromiso del SNC en los estudios autópsicos alcanza al $75 \%{ }^{(3)}$. Dado que el examen clínico y los estudios de laboratorio son insuficientes para poder establecer un diagnóstico preciso del compromiso neurológico, cobran cada vez más relevancia los estudios imaginológicos, especialmente la resonancia magnética $(\mathrm{RM})$.

Revisaremos una aproximación diagnóstica propuesta por Sibtain y colbs ${ }^{(3)}$, que hemos modificado con el objetivo de hacerla más práctica y fácil de recordar, no incluyendo lesiones muy poco frecuentes, muchas de las cuales no tienen un patrón imaginológico específico. Acompañamos nuestra revisión con ejemplos de imágenes que enfatizan los hallazgos principales y más característicos de cada patología.

\section{Aproximación diagnóstica}

Podemos agrupar los hallazgos imaginológicos en siete grandes categorías, según el hallazgo predominante (Tabla I). Debemos recordar que puede existir superposición de éstos, no siendo infrecuente la presencia de varias comorbilidades en un mismo individuo.

A continuación describiremos cada uno de estos subgrupos, con énfasis en las enfermedades más frecuentemente observadas en la práctica diaria.
Tabla I. Clasificación de los hallazgos imaginológicos

A. Compromiso difuso de la sustancia blanca

B. Compromiso focal de la sustancia blanca

C. Masa focal con realce

D. Masa focal sin realce

E. Lesión focal con realce, con nulo o escaso efecto de masa,

F. Meningitis

G. Ventriculitis

\section{A. Compromiso difuso de la sustancia blanca}

En estos casos se evidencia una alteración predominante a nivel de la sustancia blanca, que se visualiza hipodensa en tomografía computada (TC) e hiperintensa en secuencias de RM ponderadas en T2; no se observa efecto de masa ni existe realce con el uso de medio de contraste. Las dos principales etiologías causantes de este tipo de compromiso corresponden a la encefalopatía VIH y la infección por Citomegalovirus (CMV).

\section{A.1. Encefalopatía VIH}

Como ya se mencionó, el virus VIH es neurotrópico e infecta el SNC en etapas precoces de la enfermedad y por lo tanto, una de las características de esta patología es que la encefalitis por VIH se produce antes que las infecciones oportunistas.

Se estima que afecta a un $60 \%$ de los individuos con SIDA, siendo la causa más frecuente de compromiso neurológico en este grupo de pacientes.

La encefalitis VIH (EVIH), como su nombre lo indica, es causada por el propio virus $\mathrm{VIH}$; se caracteriza por la presencia de un cuadro compatible con encefalitis subaguda, acompañada de atrofia cerebral y desmielinización. Afecta principalmente a la sustancia blanca profunda y subcortical, pudiendo comprometer también los ganglios basales. Se cree que podría estar relacionada a otros virus ${ }^{(4)}$.

Estudio imaginológico. Los estudios imaginológicos revelan una atrofia cerebral difusa, con hipodensidad en la TC o un aumento de intensidad de la señal en secuencias de RM ponderadas en T2, que típicamente afectan a la región frontal subcortical y periventricular. Este compromiso suele ser bilateral, simétrico, y no suele realzar con el uso de medio de contraste. Puede existir un compromiso multifocal o parchado, sin presentar efecto de masa(3,5) (Figura 1). 


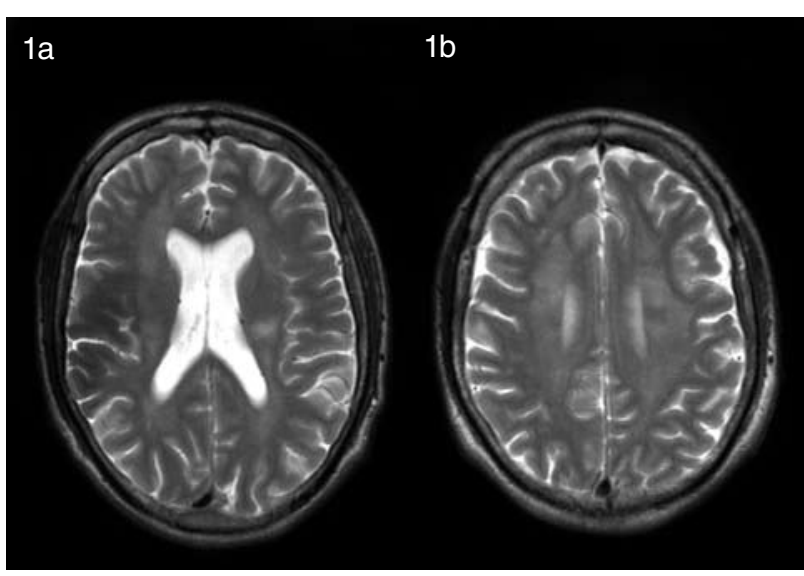

Figura 1a, b. Secuencias T2 spin-eco evidencian una alteración de señal de la sustancia blanca, simétrica y sin efecto de masa. Dg: Leucoencefalopatía VIH en paciente VIH de larga evolución, con cuadro demencial.

\section{A.2. Infección por CMV}

La infección por CMV puede cursar con una encefalopatía progresiva, aunque más comúnmente produce una meningo-encefalitis. Puede coexistir con otras entidades como la toxoplasmosis y la criptococosis. Cuando el compromiso es subagudo, la clínica es similar a la producida en la encefalopatía $\mathrm{VIH}^{(6)}$.

La infección por CMV ha sido documentada hasta en el $30 \%$ de los pacientes con SIDA, siendo la mayoría de los casos una reactivación, ya que el CMV existe en forma latente sobre el $90 \%$ de la población general.

Estudio imaginológico. Los hallazgos pueden ser similares a los descritos en la encefalopatía VIH. Ahora bien, lo más frecuente es que la hiperintensidad de la sustancia blanca sea parchada. La existencia de un realce sub-ependimario asociado corresponde a un signo muy característico pero infrecuente de CMV.

\section{B. Compromiso focal de la sustancia blanca}

En este grupo se observan lesiones que afectan predominantemente a la sustancia blanca en forma parchada, ya que los bordes de la lesión suelen ser mal definidos y no generan un efecto de masa significativo para el tamaño de la lesión.

En este grupo, las principales lesiones que debemos considerar son la leucoencefalopatía multifocal progresiva (LEMP) y la encefalopatía VIH.

\section{B.1. Leucoencefalopatía multifocal progresiva (LEMP)}

Esta afección no es propia de los pacientes con SIDA, ya que ha sido descrita también en individuos inmunodeprimidos secundarios a leucemia, posttrasplante y quimioterapia, entre otros; sin embargo, con el advenimiento del SIDA su frecuencia se ha incrementado de forma considerable. Se estima que afecta entre el 2 y $8 \%$ de los pacientes con SIDA.
Corresponde a una enfermedad progresiva que desencadena la muerte en la mayoría de los pacientes (actualmente representa el $4 \%$ de las causas de muerte de estos pacientes). Últimamente se ha evidenciado que la terapia anti-retroviral puede mejorar la sobrevida.

La LEMP corresponde a una encefalitis subaguda, secundaria a la reactivación del papovavirus JC en huéspedes inmunocomprometidos. El virus JC es ubicuo, siendo usualmente adquirido durante la infancia; el mecanismo de transmisión permanece poco claro, pero se cree que el tracto respiratorio alto puede ser el sitio inicial de infección, generalmente asintomática.

El virus infecta principalmente a los oligodendrocitos, lo que determina la desmielinización generalizada ${ }^{(3,7)}$.

Estudio imaginológico. Los hallazgos característicos corresponden a un compromiso multifocal o parchado de la sustancia blanca, clásicamente sin efecto de masa o muy escaso en relación con el grado de compromiso. Se inicia en las áreas subcorticales, afectando a las fibras en U. Se observan lesiones hipointensas en imágenes ponderadas en T1 e hiperintensas en T2, que después confluyen y se profundizan en forma bilateral pero asimétrica. La localización más frecuente es a nivel del lóbulo parietal, comprometiendo centros semiovales; el cuerpo calloso también puede ser afectado Se trata de lesiones sin signos de hemorragia y sin realce, pero si lo presentan éste es escaso y en anillo (Figura 2).

En los estudios espectroscópicos se evidencian altos niveles de mioinositol, que es considerado un marcador glial. Secundariamente a esta intensa desmielinización se evidencian altos niveles de colina, mientras que los de $\mathrm{N}$-acetil-aspartato están disminuidos, siendo este último un marcador de integridad neuronal ${ }^{(8)}$.

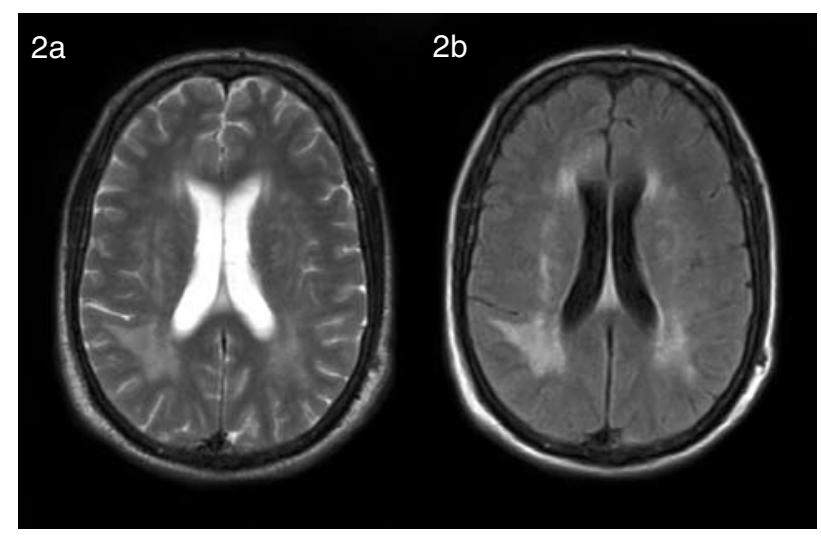

Figura 2. Secuencias T2 spin-eco (a) y T2 FLAIR (b) muestran lesión hiperintensa que compromete la sustancia blanca parietal derecha, asimétrica, asociada a un discreto efecto de masa y sin realce con el uso de gadolinio (no mostrado). Dg: Leucoencefalopatía multifocal progresiva. 


\section{B.2. EVIH}

Como se comentó previamente, la EVIH puede producir un compromiso parchado de la sustancia blanca. Es por éso que en los estudios imaginológicos, siempre debemos realizar el diagnóstico diferencial entre LEMP y EVIH (Tabla II).

\begin{tabular}{|c|c|c|}
\hline & EVIH & LEMP \\
\hline $\begin{array}{l}\text { Características } \\
\text { clínicas }\end{array}$ & $\begin{array}{l}\text { Complejo } \\
\text { demencia-SIDA }\end{array}$ & $\begin{array}{l}\text { Déficit } \\
\text { neurológico focal }\end{array}$ \\
\hline Agente & VIH-1 & Virus JC \\
\hline TC & Isodensa & Hipodensa \\
\hline $\mathrm{T} 1 / \mathrm{T} 2$ & $\begin{array}{l}\text { Isointensa / } \\
\text { Hiperintensa }\end{array}$ & $\begin{array}{l}\text { Hipointensa/ } \\
\text { Hiperintensa }\end{array}$ \\
\hline $\begin{array}{l}\text { Realce con } \\
\text { contraste }\end{array}$ & No & Ocasionalmente \\
\hline Distribución & $\begin{array}{l}\text { Bilateral, simétrica, } \\
\text { periventricular }\end{array}$ & $\begin{array}{l}\text { Unilateral, } \\
\text { asimétrica, } \\
\text { subcortical }\end{array}$ \\
\hline
\end{tabular}

\section{Masa focal con realce}

Este compromiso se caracteriza por la presencia de una lesión con efecto de masa sobre el parénquima cerebral subyacente. Como en toda lesión ocupante de espacio, observaremos desplazamiento de las estructuras encefálicas y disminución de amplitud del espacio subaracnoideo y ventricular, dependiendo de la ubicación de la lesión.

Debemos analizar varios aspectos para realizar un minucioso diagnóstico diferencial, entre los que se encuentran: número de lesiones (única o múltiple), ubicación, intensidad de señal y comportamiento con el medio de contraste. Actualmente también se debe incluir su comportamiento en difusión y el estudio espectroscópico. Las dos lesiones más características de este grupo son la toxoplasmosis y el linfoma, dos entidades que ocasionalmente pueden ser indistinguibles en los estudios imaginológicos, pero que podemos diferenciar teniendo en consideración algunos elementos que se mencionan a continuación.

\section{C.1 Toxoplasmosis}

La toxoplasmosis es producida por un protozoo denominado Toxoplasma gondii. Corresponde a la infección oportunista del SNC, más habitual en los pacientes con SIDA; afecta hasta un $50 \%$ de los pacientes que no reciben profilaxis y a un $60 \%$ de los pacientes con SIDA, siendo la causa más frecuente de lesión focal. La mayoría de los casos corresponde a una infección latente recurrente, causante generalmente de encefalitis necrotizante multifocal con formación de abscesos, que afecta principalmente los núcleos basales y la sustancia blanca subcortical.

El cuadro clínico es inespecífico, cursando con cefalea, fiebre, déficits neurológicos variables y convulsiones.

En los individuos con sospecha de toxoplasmosis cerebral se suele emplear una prueba terapéutica con evaluación seriada del curso clínico e imaginológico, con el objetivo de hacer el diagnóstico diferencial de un linfoma primario cerebral.

Estudio imaginológico. La toxoplasmosis se caracteriza por producir lesiones focales que miden entre 1 y $3 \mathrm{~mm}$ de diámetro, múltiples en el $85 \%$ de los casos. Estas lesiones son hipodensas en TC, iso e hiperintensas en secuencias ponderadas en $\mathrm{T} 1$ y $\mathrm{T} 2$ respectivamente, con realce en anillo. Determinan efecto de masa y se rodean de edema vasogénico en forma variable. Es frecuente el compromiso de los ganglios basales (75-88\%) y de la región subcortical. La hemorragia es rara, al igual que la ausencia de realce (Figura 3 ).

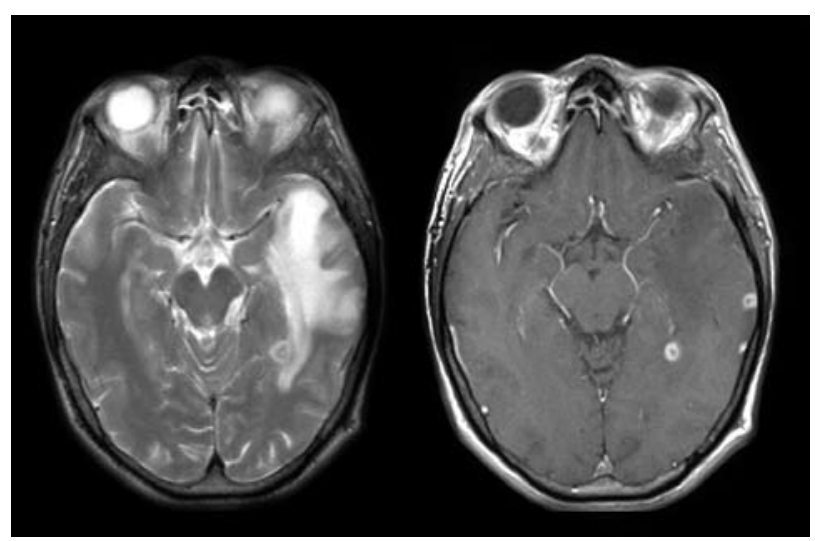

Figura 3. Secuencias T2 spin-eco (a) y T1 gadolinio (b) muestran lesiones hiperintensas en secuencias T2 circundadas por marcado edema vasogénico y realce en anillo, en situación periventricular y subcortical. Dg: Toxoplasmosis.

Los estudios espectroscópicos muestran peak de lactato y lípidos, ambos marcadores del metabolismo anaerobio, con disminución de la colina, fosfocreatina y mioinositol, marcadores de membrana y del metabolismo. Es necesario considerar que estos estudios no permiten diferenciar esta entidad del linfoma ${ }^{(8,9)}$.

\section{C.2 Linfoma primario del SNC (LPSNC)}

EI LPSNC ha presentado un incremento en su incidencia, debido a los pacientes con SIDA. EI $50 \%$ de los LPSNC se produce en estos pacientes, comprometiendo entre el 2 y $5 \%$ de los pacientes con SIDA. La mayoría corresponde a linfomas de tipo no Hodgkin, que se presentan como masas intra-axiales a diferencia del linfoma metastásico, que compromete fundamentalmente las leptomeninges. Afecta pre- 
dominantemente la región supra-tentorial, pudiendo manifestarse como masas únicas o múltiples.

Estudio imaginológico. Se observan lesiones focales, clásicamente hiperdensas en TC debido a la alta relación núcleo/citoplasma de las células malignas, lesiones que afectan preferentemente las regiones periventriculares. En la RM corresponden a lesiones iso o hipointensas en secuencias T2. Tras la administración de medio de contraste, se observa un realce intenso y homogéneo. Lamentablemente, en los pacientes VIH la presentación puede ser atípica, con áreas hemorrágicas y necróticas que varían la apariencia de la lesión (Figura 4).

Como se mencionó, la espectroscopía tampoco permite diferenciar estas lesiones de la toxoplasmosis cerebral ${ }^{(9)}$; sin embargo, se pueden dar algunas pautas que permiten diferenciar estas dos lesiones (Tabla III).

\section{C.3 Otras masas focales con realce}

Existe otra serie de lesiones que pueden presentarse como procesos expansivos con realce en los estudio imaginológicos, destacando la criptococosis y las infecciones por micobacterias.

\section{C.3.1 Criptococosis}

Enfermedad producida por el Crytococcus neoformans; corresponde a la tercera infección más frecuente después de la Toxoplasmosis y el CMV. Si bien la manifestación más frecuente es la formación de criptococomas en el espacio subaracnoideo y en los espacios perivasculares de Virchow Robin, también se pueden producir lesiones intraparenquimatosas que se presentan como masas sólidas con realce periférico y edema variable ${ }^{(10)}$.

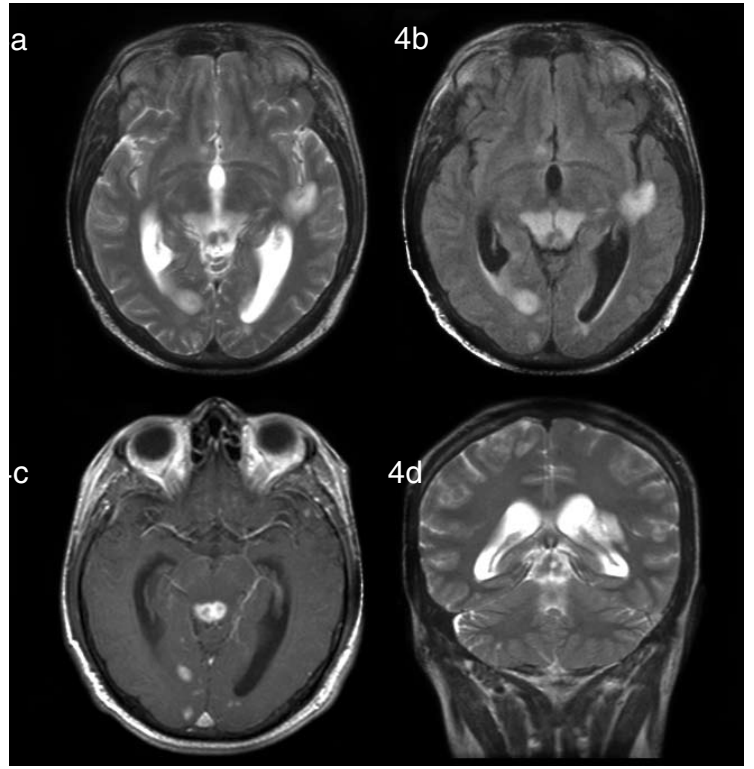

Figura 4. Secuencias T2 spin-eco (a), T2 FLAIR (b), T1 gadolinio (c) y T2 spin-eco coronal (d). Presencia de lesiones hipointensas en secuencias T2 bordeadas por edema vasogénico y realce homogéneo, que plantean diagnóstico diferencial entre toxoplasmosis y linfoma. La biopsia confirmó el diagnostico de linfoma.

\section{C.3.2 Micobacterias}

La tuberculosis del SNC es una complicación conocida en los pacientes VIH; se estima que afecta a un $10 \%$ de los pacientes VIH. Frecuentemente se asocia a un compromiso pulmonar que alcanza hasta 2/3 de los pacientes.

Estudio imaginológico. Además del compromiso meníngeo típico de la TBC, se manifiesta por lesiones intraparenquimatosas denominadas tuberculomas, que corresponden a lesiones granulomatosas, generalmente

Tabla III. Comparación entre la toxoplasmosis cerebral y el LPSNC (Modificado de Sibtain y colbs ${ }^{(3)}$ ).

\begin{tabular}{|lll|} 
& Toxoplasmosis & Linfoma \\
\hline Tamaño de las lesiones & $<4 \mathrm{~cm}$ & $>4 \mathrm{~cm}$ \\
Número de lesiones & Múltiples & Solitarias/escasas \\
Distribución & Ganglios basales, interfase & Periventricular \\
gris/blanca & \\
Hemorragia & + & $+/-$ \\
Edema & +++ & + \\
Realce & En anillo, de paredes delgadas & Anillo de espesor irregular, \\
Efecto de masa & +++ & heterogéneo \\
Cuerpo calloso & Raramente involucrado & + \\
\hline
\end{tabular}


múltiples y menores de $1 \mathrm{~cm}$ de diámetro. Se ubican preferentemente en la unión de sustancia blanca-gris, rodeadas por escaso o nulo edema vasogénico. Tras la administración de contraste presentan un realce nodular o en anillo; se describe también en target, que si bien no es específico o patognomónico de esta patología, es bastante sugerente de la enfermedad ${ }^{(11)}$ (Figura 5).

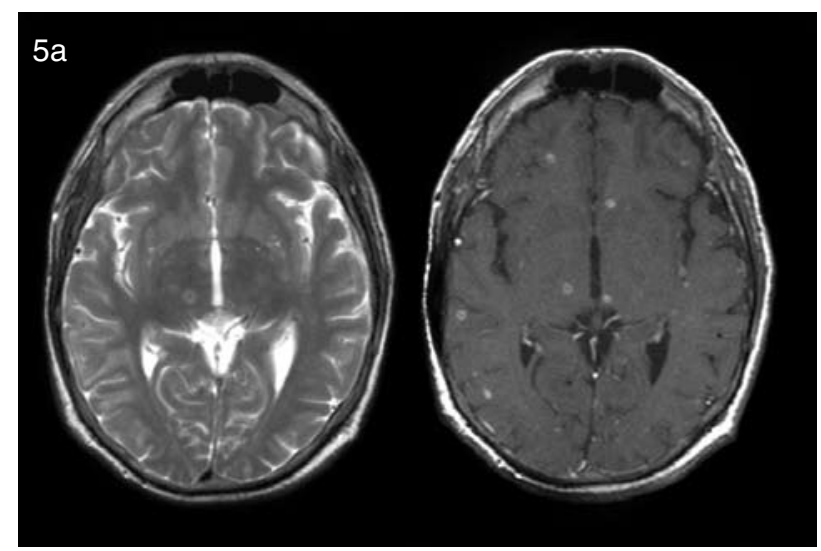

Figura 5. Secuencias T2 spin-eco (a) y T1 gadolinio (b). Múltiples lesiones discretamente hiperintensas y de centro isointenso en secuencias T2, que presentan escaso edema vasogénico y claro realce en anillo con el contraste. La biopsia fue compatible con TBC.

\section{Masas focales sin realce}

En este grupo observamos lesiones focales que determinan efecto de masa sobre el parénquima cerebral adyacente pero que no presentan realce con el medio de contraste.

Al igual que en las lesiones del grupo anterior, debemos analizar varios aspectos para poder realizar un diagnóstico diferencial correcto: ubicación, número de lesiones y densidad o intensidad de señal.

La lesión más característica de este grupo es la criptococosis y rara vez estas lesiones pueden corresponder a toxoplasmosis o linfoma.

\section{D.1. Criptococosis}

Como se mencionó anteriormente, corresponde a la tercera infección más frecuente después de la toxoplasmosis y el CMV. Entre el 5 a 10\% de los pacientes infectados por el virus desarrollarán esta patología. Característicamente, el Criptococo produce un material mucoide formando criptococomas en el espacio subaracnoideo y en los espacios perivasculares de Virchow Robin. Estas lesiones suelen ser de pequeño tamaño y no presentan realce porque no producen alteraciones de la barrera hemato encefálica.

Estudio imaginológico. Son lesiones hipodensas en TC y en RM siguen la señal del LCR, aunque se han descritos lesiones espontáneamente hiperintensas en secuencias $\mathrm{T} 1$, por un alto contenido proteináceo ${ }^{(10)}$.
Estas lesiones determinan efecto de masa pero raramente se acompañan de edema vasogénico (Figura 6).

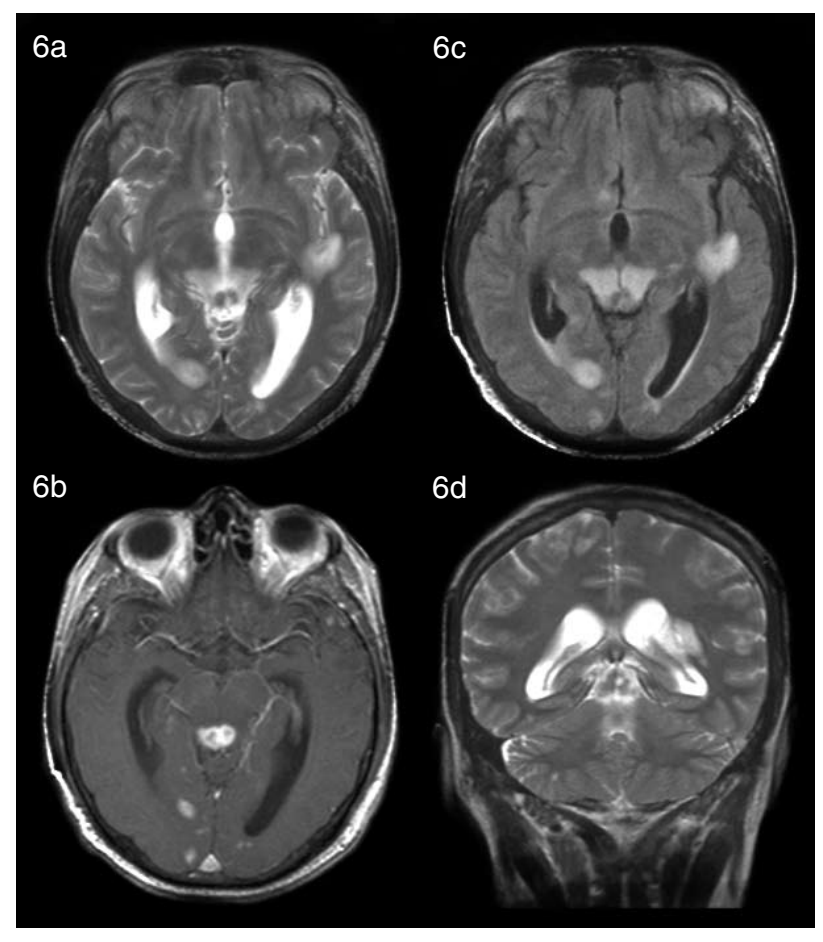

Figura 6. Secuencias T2 spin-eco axial (a) coronal (b) y T1 gadolinio axial (c) sagital (d) evidencian múltiples lesiones que siguen la señal del LCR en el espacio subaracnoídeo de surcos corticales y espacios perivasculares. Dg: Criptococosis en paciente VIH que abandonó terapia retroviral. El diagnóstico se confirmó por estudio de LCR.

\section{D.2. Toxoplasmosis y linfoma}

Si bien las lesiones de la toxoplasmosis suelen realzar con el medio de contraste, a veces este realce es muy sutil o está ausente en pacientes con una severa depresión de su inmunidad. Del mismo modo se han descrito presentaciones de linfoma sin relace y un punto importante a considerar es el uso de corticoides, que pueden determinar ausencia de realce de las lesiones al reponer la integridad de la barrera hematoencefálica.

\section{E. Lesión focal con realce, con nulo o escaso efecto de masa}

Esta categoría incluye una serie de lesiones que revisaremos someramente, pero que hay que tener en consideración en el diagnóstico diferencial imaginológico, ya que suelen ser entidades difíciles de caracterizar o presentaciones inhabituales de algunas de las entidades ya revisadas.

\section{E.1. Infarto cerebral}

Los pacientes VIH tienen una incidencia aumentada de enfermedades cerebrovasculares si se 
comparan con la población general, lo que se explica por dos motivos: por un lado existe una vasculopatía causada por el virus VIH y, en segundo lugar muchas enfermedades infecciosas, sobretodo las que afectan el espacio subaracnoideo, que determinan una vasculitis, vasoespasmo y trombosis de los vasos sanguíneos; ésto se observa clásicamente en pacientes con TBC y neurosífilis. Se han descrito también vasculitis secundarias a toxoplasmosis, CMV y virus varicela zoster.

Se estima que hasta un $2 \%$ de los pacientes VIH presentará alguna manifestación de enfermedad cerebrovascular en el curso de su enfermedad.

La apariencia de los infartos no varía en relación con los encontrados en la población general, con la única diferencia que la mayoría de los infartos cerebrales en este grupo de pacientes son silentes ${ }^{(12)}$. Por lo mismo, no es raro observarlos en fases subagudas con realce cortical, hallazgo que nos debe hacer plantear esta entidad si respeta un territorio vascular.

\section{E.2. Encefalitis viral}

La encefalitis en este grupo de pacientes puede variar de la clásica presentación secundaria al virus Herpes simples, observada en la población general. Se pueden evidenciar áreas de realce cortical con escaso efecto de masa, por lo que siempre ante un realce cortical que no respeta un territorio vascular se debe plantear la posibilidad de una encefalitis, complicación rara del SIDA que ha sido reportada en el $2 \%$ de las autopsias.

\section{E.3. Toxoplasmosis}

Si bien es cierto que corresponde a una presentación poco frecuente, podemos observar una fase de cerebritis previa a la formación de un absceso. Esto ocurre sobretodo en pacientes con un severo estado de inmunosupresión.

\section{E.4. Cerebritis bacteriana}

Al igual que en la población general, los casos de cerebritis bacteriana son raros de observar. La mayoría de los pacientes se presentan en etapas más tardías con formación de un absceso.

\section{E.5. LEMP}

Una forma de presentación poco frecuente de la LEMP corresponde a una lesión que compromete la sustancia blanca, con escaso efecto de masa y con realce $^{(13)}$. El realce clásicamente es discreto y periférico; estaría en relación a una respuesta inmunológica al papovavirus $J C$.

\section{F. Meningitis}

Las meningitis en este grupo de pacientes es un hallazgo frecuente. Como ya hemos visto, muchas patologías pueden comprometer no sólo el parénquima cerebral sino también las meninges (meningoencefali- tis). El mismo virus VIH en estado de seroconversión puede manifestarse como una meningoencefalitis.

\section{F.1. Criptococosis}

Como se mencionó, el Criptococo puede comprometer las meninges y producir una meningitis con o sin formación de criptococomas, determinando en los estudios imaginológicos un aumento de intensidad de señal del espacio subracnoideo en secuencias FLAIR y, un realce leptomeníngeo difuso(10) (Figura 7).

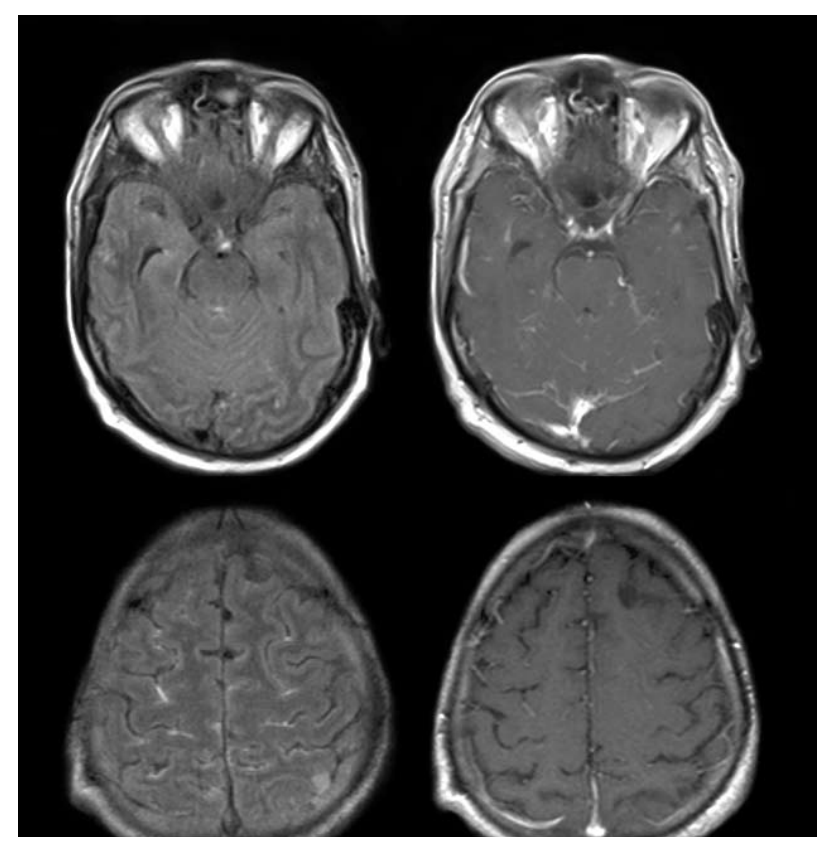

Figura 7. Secuencias T2 FLAIR ( $a$ y b) y T1 gadolinio (c y d). Aumento de intensidad de señal del espacio subaracnoídeo en secuencia FLAIR asociado a realce leptomeníngeo, en paciente $\mathrm{VIH}$ con cuadro de meningismo progresivo. Se confirmó una meningitis secundaria a criptococo.

\section{F.2. TBC}

Clásicamente la TBC produce un cuadro de meningitis basal con engrosamiento de las meninges, preferentemente de las cisternas de la base, evidenciándose un marcado realce con el uso de medio de contraste. Se suele acompañar de una hidrocefalia comunicante.

\section{F.3. Neurosífilis}

Se puede observar un cuadro de meningitis en casos de neurosífilis, manifestándose en los estudios imaginológicos como un realce leptomeníngeo difuso o focal.

\section{G. Ventriculitis}

La inflamación del epéndima ventricular es una entidad poco frecuente, que conlleva una alta morbimortalidad. En los pacientes VIH, clásicamente es secundaria al CMV y a otros virus de la familia herpesviridae. 


\section{G.1. CMV}

La infección por CMV puede producir una ventriculoencefalitis que clásicamente se manifiesta por una hipodensidad o hiperintesidad de la sustancia blanca peri-ventricular en secuencias T2, hallazgo que se asocia a un realce subependimario fino y difuso. Hallazgos similares pueden verse en casos de virus Herpes zoster ${ }^{(14)}$.

\section{Conclusiones}

El compromiso del SNC en los pacientes VIH es una causa frecuente morbimortalidad. En este grupo de pacientes el diagnóstico etiológico de las enfermedades del SNC es difícil desde el punto de vista clínico y de laboratorio, dada la superposición de los hallazgos. Los estudios imaginológicos, si bien no están exentos de problemas, han demostrado ser una importante herramienta diagnóstica y de seguimiento en este grupo de pacientes.

Un análisis minucioso de los hallazgos imaginológicos y el conocimiento de las enfermedades más frecuentes nos permiten una adecuada aproximación etiológica. La clasificación de los hallazgos en algunas de las categorías que hemos presentado, más un análisis de la ubicación, número, señal o densidad de las lesiones nos permiten acercarnos bastante al diagnóstico o al menos, establecer un diagnóstico diferencial razonable de las posibles etiologías.

\section{Bibliografía}

1. Joint United Programme on VIH/SIDA (UNAIDS) / World Health Organization (WHO). Guidelines for effective use of data from HIV surveillance systems. 2004.

2. Martínez P, Olea A, Chiu M. Situación epidemiológica de la infección por VIH y el síndrome de inmunodeficiencia adquirida en Chile. Rev Chil Infect 2006; 23 (4): 321-329.

3. N A Sibtain, MRCP and R J S Chinn, MRCP, FRCR. Imaging of the central nervous system in HIV infection. Imaging 2002; 14: 48-59.

4. Budka H. Human immunodeficiency virus (HIV) induced disease of the central nervous system: pathology and implications for pathogenesis. Acta Neuropathol 1989; 77: 225-236.

5. Janaki Balakrisbnan P. Scott Becker AsbokJ. Kumar S. James Zinreich MD, Justin C. McArtbur R. Nick Bryan. Acquired Immunodeficiency Syndrome: Correlation of Radiologic and Pathologic Findings in the Brain. RadloGraphics 1990; 10: 201-215.

6. Holland NR, Power C, Matthews VP, Glass VD, Forman M, McArthur JC. Cytomegalovirus encephalitis in acquired immunodeficiency síndrome (AIDS). Neurology 1994; 44: 507-514.

7. Whiteman ML, Post JD, Berger JR, Tate LG, Bell MD, Limonte LP. Progressive multifocal leucoencephalopathy (PML) in 47 HIV-seropositive patients: neuroimaging with clinical and pathologic correlation. Radiology 1993; 187: 233-240.

8. Chang L, Ernst T. MR spectroscopy and diffusionweighted MR imaging in focal brain lesions in AIDS. Neuroimag Clin North Am 1997; 7: 409-426.

9. Chinn, ID Wilkinson, MA Hall-Craggs, MN Paley, RF Miller, BE Kendall, SP Newman and MJ Harrison. Toxoplasmosis and primary central nervous system lymphoma in HIV infection: diagnosis with MR spectroscopy. Radiology 1995; 197: 649-654.

10. Wehn SM, Heinz ER, Burger PC, Boyko OB. Dilated Virchow-Robin spaces in cryptococcal meningitis associated with AIDS: CT and MR findings. J Comput Assist Tomogr 1989; 13: 756-762.

11. Hansman Whiteman ML. Neuroimaging of central nervous system tuberculosis in HIV infected patients. Neuroimaging Clin N Am 1997; 7: 199-214.

12. Gillams AR, Allen E, Hrieb K, Venna N, Craven D, Carter AP. Cerebral infarction in patients with AIDS. Am J Neuroradiol 1997; 18: 1581-1585.

13. Collazos J, Mayo J, Martinez E, Blanco MS. Contrastenhancing progressive multifocal leucoencephalopathy as an immune reconstitution event in AIDS patients. AIDS 1999; 13: 1426-1428.

14. Wright D, Schneider A, Berger J. Central nervous system opportunistic infections. Neuroimaging $\mathrm{ClinN}$ Am 1997; 7: 513-525. 